\title{
Synthesis and Intermolecular Hydrogen Bonding of Nickel(II) Dithiocarbamates of amino acids
}

\author{
NOMURA Ryôki ${ }^{* 1,2}$, TOMINAGA Kouji ${ }^{1}$, OHTAKA Atushi $^{1}$, and SHIMOMURA Osamu ${ }^{1}$ \\ ${ }^{1}$ Department of Chemistry and ${ }^{2} \mathrm{NMRC}$, Osaka Institute of Technology, Ô-Miya, Asahi, Osaka, 535-5858, Japan \\ E-mail: nomura@chem.oit.ac.jp
}

\begin{abstract}
Nickel(II) dithiocarbamates from glycine(1), $\beta$-alanine(2), 4-aminobutyric acid(3) and 5 -aminovaleric acid(4) were synthesized successfully from their triethylammonium dithiocarabamate salts. Among them, complex 1 formed a linear polymer through a cumulative face-to-face hydrogen bonding between terminal carboxylic moieties. Complexes 2-4 showed similar broad absorption bands to 1 assignable to carboxylic moiety with hydrogen bonding. These broad absorption bands suggested the formation of linear polymers connected with such hydrogen bondings.

Key words: Ni(II) dithiocabamate, hydrogen bonding, complex assemblies, amino acid
\end{abstract}

\section{INTRODUCTION}

Recently, much attempt has been done to accumulate transition metal complexes to form supramolecules. Higher dimensional structure with specific microchannels of such the supramolecular complex assemblies show some specific functions, especially selective adsorption of small molecules, which the individual complexes can not offer [1-2].

In our continuous studies on the transition metal dithiocarbamate, some nickel dithiocarbamate complexes having active hydrogens other than carbamoyl protons were found to form self-organized assemblies via intermolecular hydrogen bondings [3]. Further, an introduction of amino acid ester moieties within the dithiocarbamate ligand such as glycine methyl etc., drived 3-D self-organization, and such nickel dithiocarbamate complexes also formed a chlathrate with 4,4'-bipyridine through intermolecular hydrogen bondings [4].

In this study, we tried to synthesize novel nickel(II) dithiocarbamate complexes of amino acid aiming to lead a different type of complex assembly, and investigated intermolecular interaction of these complexes.

\section{EXPERIMENTAL}

\subsection{Characterization}

IR, ${ }^{1} \mathrm{H}$ - and ${ }^{13} \mathrm{C}-\mathrm{NMR}$ and Uv-vis spectra were recorded with a SHIMADZU FT-IR DR8500 spectrophotometer, a Varian UNITY300 $(300$ $\mathrm{MHz}$ ) spectrometer and a SHIMADZU UV-2450PC spectrophotometer, respectively. Single crystal automatic $\mathrm{X}$-ray structure analysis was done with a Rigaku AFC-7R four-circle $X$-ray diffractometer. The structure analyses of crystals were performed over the reflection range within $4.0^{\circ}<2 \theta<120.1^{\circ}$ by the $\omega$ - $2 \theta$ scanning using $\mathrm{Cu} K_{\mathrm{a}}$ radiation $(1.54178 \AA)$ at room temperature $(298 \mathrm{~K})$. In addition, the structures were solved by the Crystal Structure program
[5,6]. We could get refined structure of bis(hydroxycarbonylmethyldithiocarbamato) nickel(11), complex 1, using the Direct Method (SIR92) $[7,8]$.

\subsection{Synthesis}

General synthetic method for the complexes having carboxyl groups at the end of ligands is as following. Amino acids (5 mmol) such as glycine, $\beta$-alanine, 4-aminobutyric acid or 5 -aminovaleric acid were placed in a $100 \mathrm{~mL}$ flask. Then, distilled water $(10 \mathrm{~mL})$ and triethylamine $(5 \mathrm{mmol})$ were added to the flask and the resulted solution was stirred at room temperature for $1 \mathrm{~h}$. Afterwards, the mixture of methanol $(10 \mathrm{~mL})$ and carbon disulfide $(5 \mathrm{mmol})$ was slowly added drop-by-drop to the solution under cooling. The mixture was stirred for additional $24 \mathrm{~h}$ at room temperature. After the reaction, the solvent and the volatiles were removed under reduced pressure to obtain the corresponding triethylammonium dithiocarbamate salts. Nickel(II) chloride $(1.5 \mathrm{mmol})$ in 1 mol $\cdot \mathrm{dm}^{-3}$ hydrochloric acid $(10 \mathrm{~mL})$ were added drop-by-drop to the aqueous solution of the salts. During the addition of nickel salt, precipitates formed immediately, which were filtered off, washed with pure water and dried under reduced pressure at room temperature.

The complexes of amino acid methyl esters, which have same amino acid residues as 1-4 was prepared with the reported procedure[4] and numbered as 5-8.

Identification of $\mathrm{Ni}\left(\mathrm{S}_{2} \mathrm{CNHCH}_{2} \mathrm{CO}_{2} \mathrm{H}\right)_{2}(1)$, Ni$\left[\mathrm{S}_{2} \mathrm{CNH}\left(\mathrm{CH}_{2}\right)_{2} \mathrm{CO}_{2} \mathrm{H}\right]_{2}$ (2), Ni[S $\mathrm{CNH}\left(\mathrm{CH}_{2}\right)_{3}-$ $\left.\mathrm{CO}_{2} \mathrm{H}\right]_{2}$ (3), $\mathrm{Ni}\left[\mathrm{S}_{2} \mathrm{CNH}\left(\mathrm{CH}_{2}\right)_{4} \mathrm{CO}_{2} \mathrm{H}\right]_{2}$ (4) was done with IR, ' $\mathrm{H}$ - and ${ }^{13} \mathrm{C}-\mathrm{NMR}$ spectra and elemental analyses. Results of the preparation and spectral data of these complexes are shown in Table I, II, and III. 
Table I. Characteristics of complexes 1-8

\begin{tabular}{|c|c|c|c|}
\hline Complexes & & $\%$-yield & $\mathrm{mp} /{ }^{\circ} \mathrm{C}$ \\
\hline $\mathrm{Ni}\left(\mathrm{S}_{2} \mathrm{CNHCH}_{2} \mathrm{CO}_{2} \mathrm{H}\right)_{2}$ & 1 & 84 & $205.0-206.0$ \\
\hline $\mathrm{Ni}\left[\mathrm{S}_{2} \mathrm{CNH}\left(\mathrm{CH}_{2}\right)_{2} \mathrm{CO}_{2} \mathrm{H}\right]_{2}$ & 2 & 72 & -156.5 \\
\hline $\mathrm{Ni}\left[\mathrm{S}_{2} \mathrm{CNH}\left(\mathrm{CH}_{2}\right)_{3} \mathrm{CO}_{2} \mathrm{H}_{2}\right.$ & 3 & 76 & 175.0 \\
\hline $\mathrm{Ni}\left[\mathrm{S}_{2} \mathrm{CNH}\left(\mathrm{CH}_{2}\right)_{4} \mathrm{CO}_{2} \mathrm{H}\right]_{2}$ & 4 & 81 & 163.0 \\
\hline $\mathrm{Ni}\left(\mathrm{S}_{2} \mathrm{CNHCH}_{2} \mathrm{CO}_{2} \mathrm{Me}\right)_{2}$ & 5 & 41 & -205.5 \\
\hline $\mathrm{Ni}\left[\mathrm{S}_{2} \mathrm{CNH}\left(\mathrm{CH}_{2}\right)_{3} \mathrm{CO}_{2} \mathrm{Me}_{2}\right.$ & 6 & 18 & $186.0-187.0$ \\
\hline $\mathrm{Ni}\left[\mathrm{S}_{2} \mathrm{CNH}\left(\mathrm{CH}_{2}\right)_{4} \mathrm{CO}_{2} \mathrm{Me}\right]_{2}$ & & 22 & $180.5-181.5$ \\
\hline $\mathrm{Ni}\left[\mathrm{S}_{2} \mathrm{CNH}\left(\mathrm{CH}_{2}\right)_{5} \mathrm{CO}_{2} \mathrm{Me}_{2}\right.$ & & 10 & $152.0-153.0$ \\
\hline
\end{tabular}

Table II. IR spectral data of complexes 1-8

\begin{tabular}{ccccc}
\hline \multirow{2}{*}{ complexes } & \multicolumn{4}{c}{ absorption center $/ \mathrm{cm}^{-1}$ a) } \\
\cline { 2 - 5 } & $v(\mathrm{~N}-\mathrm{H})$ & $v(\mathrm{C}=\mathrm{O})$ & $v(\mathrm{C}-\mathrm{N})$ & $v(\mathrm{C}=\mathrm{S})$ \\
\hline 1 & 3344 & 1703 & 1495 & 999 \\
2 & 3281 & 1728 & 1522 & 957 \\
3 & 3342 & 1705 & 1490 & 999 \\
4 & 3314 & 1685 & 1541 & 959 \\
5 & 3279 & 1722 & 1522 & 964 \\
6 & 3275 & 1709 & 1524 & 953 \\
7 & 3234 & 1719 & 1533 & 1109 \\
8 & 3258 & 1720 & 1529 & 988 \\
\hline
\end{tabular}

a) Complexes 1-4 showed characteristic broad absorption bands at between 2500 and $2900 \mathrm{~cm}^{-1}$ assignable to $\mathrm{vOH}$ of carboxylic acid with hydrogen bonding.

Table III. Selected spectral data of complexes 1-8

\begin{tabular}{|c|c|c|c|}
\hline complexes & $\begin{array}{l}\text { TH-NMR } \\
\delta\left(\mathrm{S}_{2} \mathrm{CNH}\right)\end{array}$ & $\begin{array}{l}{ }^{13} \mathrm{C}-\mathrm{NMR} \\
\delta\left(\mathrm{S}_{2} \mathrm{CNH}\right)\end{array}$ & color \\
\hline 1 & 10.8 & 208 & dark green \\
\hline 2 & 10.5 & 206 & dark green \\
\hline $\mathbf{3}$ & 10.5 & 206 & dark green \\
\hline 4 & 10.5 & 205 & dark green \\
\hline 5 & 10.9 & 209 & dark green \\
\hline 6 & 10.5 & 206 & dark green \\
\hline 7 & 10.5 & 205 & dark green \\
\hline 8 & 10.5 & 205 & dark green \\
\hline
\end{tabular}

\section{RESULTS AND DISCUSSION}

3.1 Synthesis

It is difficult to prepare dithiocarabamate complexes of $\omega$-amino acids because of their zwitterionic nature. While, two step preparation process has been reported using $\mathrm{Ba}(\mathrm{OH})_{2}[9,10]$, however, strongly basic $\mathrm{Ba}(\mathrm{OH})_{2}$ should affect the decomposition of the complexes. Thus the reactions using $\mathrm{Ba}(\mathrm{OH})_{2}$ should be limited to the simple amino acid derivatives such as glycine and be employed at low reaction temperatures. Thus we tried to develop a novel route to such nickel (II) dithiocarbamate complexes. Consequently we attempted the metathesis reaction of nickel chloride with the corresponding dithiocarbamic acid triethylammonium salts. Then it was found that nickel (II) dithiocarbamate complexes of the amino acids 1-4 are synthesized by this new route under mild conditions in good yields. Additionally we could prepare three nickel dithiocarbamate complexes of amino acids 2-4 using this new process for the first time. The procedure of the preparation of the complexes is showed in Scheme 1.

Scheme 1 Preparation procedures for complex 1-4

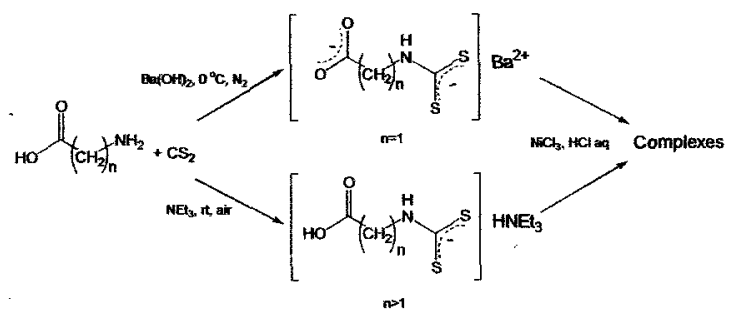

3.2 Intermolecular hydrogen bonding

Molecular structure for 1 in ORTEP drawing [11] is illustrated in Figure 1 . Complex 1 is monomeric and have planar four-coordinated geometry. Surprisingly, the whole structure of complex 1 is flat in contrast to the dithiocarbamates of amino acid esters [4].

Molecular packing diagram and hydrogen bonding sites and distance of complexes 1 were also shown in Figures 2 and 3 , respectively. Complex 1 formed intermolecular and complementary hydrogen bonding between the terminal carboxylic moieties. The distance of hydrogen bonding of complex 1 is estimated as $0.26 \mathrm{~nm}$. It was found that complex 1 formed a 1-D liner chain. The mode of complementary hydrogen bonding is similar to that in the organic carboxylic acid dimers.

Crystallographic data by single crystal automatic $X$-ray structure analysis of complex 1 are shown in Table IV.

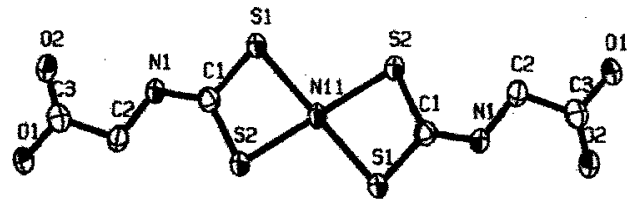

Figure 1 An ORTEP drawing of complex 1.

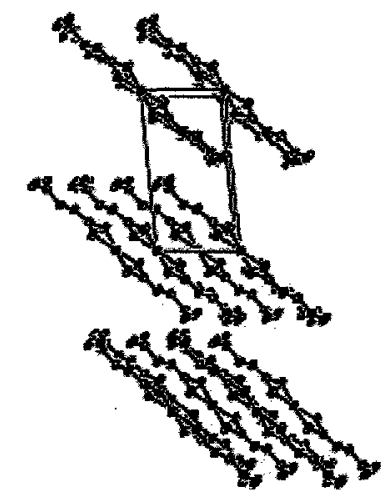

Figure 2 Molecular packing diagrams of complex 1 
viewed along $c$-axis to the [010] direction.

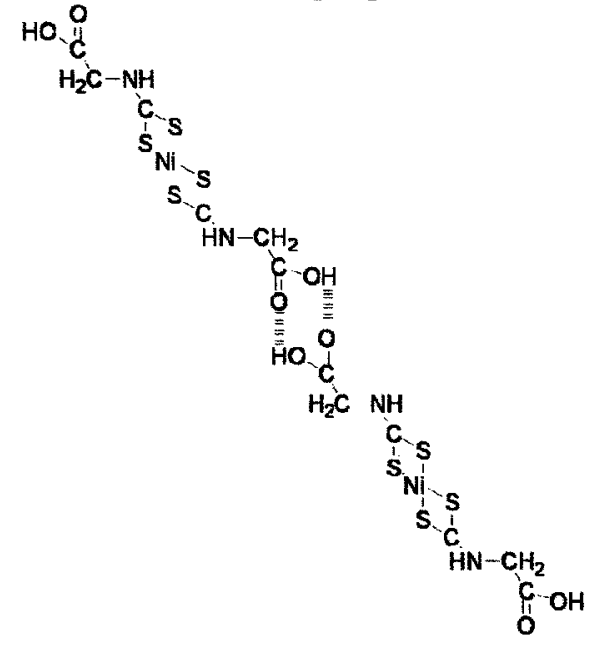

Figure 3 Intermolecular $(0.26 \mathrm{~nm})$ hydrogen bonding in complexes 1 .

Table V Crystallographic data for complex 1

\begin{tabular}{cc}
\hline Description & $\mathrm{Ni}\left(\mathrm{S}_{2} \mathrm{CNHCH}_{2} \mathrm{CO}_{2} \mathrm{H}_{2}\right.$ \\
\hline Formula & $\mathrm{NiC}_{6} \mathrm{H}_{8} \mathrm{~N}_{2} \mathrm{O}_{4} \mathrm{~S}_{4}$ \\
Formula weight & 359.08 \\
$T /{ }^{\circ} \mathrm{C}$ & 25.0 \\
Crystal system & Monolic \\
Space group & $\mathrm{P}_{1} /(\# 14)$ \\
$a / \AA$ & $5.627(3)$ \\
$b / \AA$ & $10.267(3)$ \\
$c / \AA$ & $10.584(2)$ \\
$\beta / \circ$ & $95.97(3)$ \\
$V / \AA^{3}$ & $608.1(3)$ \\
$\mathrm{Z}$ & 2 \\
$D($ calc. $) / \mathrm{g} \cdot \mathrm{cm}{ }^{-3}$ & 1.961 \\
Crystal size $/ \mathrm{nm}$ & $0.20 \times 0.10 \times 0.05$ \\
Monochromater & $\mathrm{CuKa}(\lambda=1.54178 \AA)$ \\
$F(000)$ & 364.00 \\
No.reflections & \\
Total & 1006 \\
Unique & 899 \\
Observed & 764 \\
$R[I>2 \sigma(I)]$ & \\
$R$ & 0.0534 \\
$R_{w}$ & 0.0448 \\
\hline
\end{tabular}

Unfortunately we could not obtain single crystals of complexes 2-4 suitable for structure analyses. However, these three complexes show similar broad absorption bands assignable to $v(\mathrm{COOH})$. Thus, complexes 2-4 perhaps have the similar structure to complex 1 and formed a linear polymer through intermolecular hydrogen bonding between terminal carboxylic moieties.

Previously, we prepared the dithiocarbamate complexes having amino acid ester moieties and their molecular and assembled structures through hydrogen bonding between carbamoyl and terminal ester were thoroughly investigated; e.g., four complexes 5-8. Typical IR spectra of complex 1 and 5 are displayed in Figure 4 and absorption maxima of $\mathrm{v}\left(\mathrm{S}_{2} \mathrm{CN}-\mathrm{H}\right)$ of complex 1-8 are summarized in Table $\mathrm{V}$ and it was found that complexes 1-4 showed higher wavenumber shifts comparing to 5-8, which suggested that the carbamoyl protons of complexes 1-4 are free. Consequently, complexes 5-8 should offer complex assemblies through hydrogen bonding between carbamoyl protons and terminal ester carbonyls.

\section{(a)}

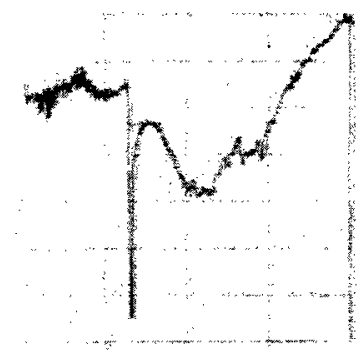

(b)

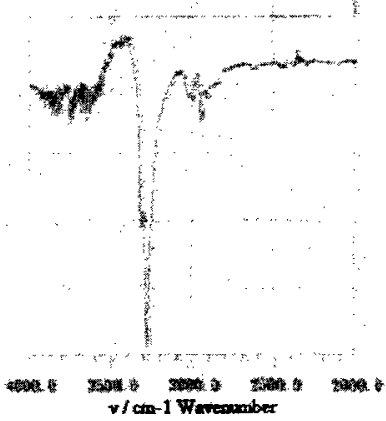

Figure 4 Comparative infrared spectra of (a) complex 1 and (b) complex 5.

Table V Infrared spectra of dithiocarbamoyl proton of complex 1-8

\begin{tabular}{|c|c|c|c|c|}
\hline \multirow{2}{*}{ complexes } & \multicolumn{4}{|c|}{$\mathrm{v}\left(\mathrm{S}_{2} \mathrm{CN}-\mathrm{H}\right) / \mathrm{cm}^{-1}$} \\
\hline & & $\mathrm{R}=\mathrm{H}$ & & $\mathrm{R}=\mathrm{Me}$ \\
\hline $\mathrm{Ni}\left(\mathrm{S}_{2} \mathrm{CN} / \mathrm{CH}_{2} \mathrm{CO}_{2} \mathrm{R}\right)_{2}$ & 1 & 3344 & 5 & 3279 \\
\hline $\mathrm{Ni}\left[\mathrm{S}_{2} \mathrm{CN} H\left(\mathrm{CH}_{2}\right)_{2} \mathrm{CO}_{2} \mathrm{R}\right]_{2}$ & 2 & 3281 & 6 & 3275 \\
\hline $\mathrm{Ni}\left[\mathrm{S}_{2} \mathrm{CN} /\left(\mathrm{CH}_{2}\right)_{3} \mathrm{CO}_{2} \mathrm{R}\right]_{2}$ & 3 & 3342 & 7 & 3234 \\
\hline $\mathrm{Ni}\left[\mathrm{S}_{2} \mathrm{CN} /\left(\mathrm{CH}_{2}\right)_{4} \mathrm{CO}_{2} \mathrm{R}\right]_{2}$ & 4 & 3314 & 8 & 3258 \\
\hline
\end{tabular}

Molecular structure, molecular packing diagrams and hydrogen bonding distance of complexes 8 are also shown in Figures 5-7, respectively. Complex 8 formed 1-D polymer by intermolecular hydrogen bonding between dithiocarmoly proton and terminal ester carbonyl. In addition, intermolecular hydrogen bonding distance was $0.29 \mathrm{~nm}$ which is as same as that of complex 5 [4].

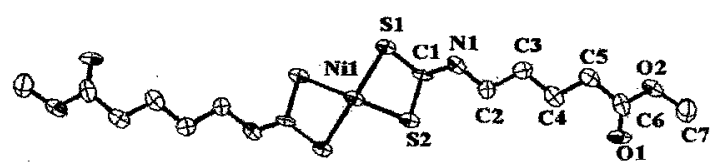

Figure 5 An ORTEP drawing of complex 8. 


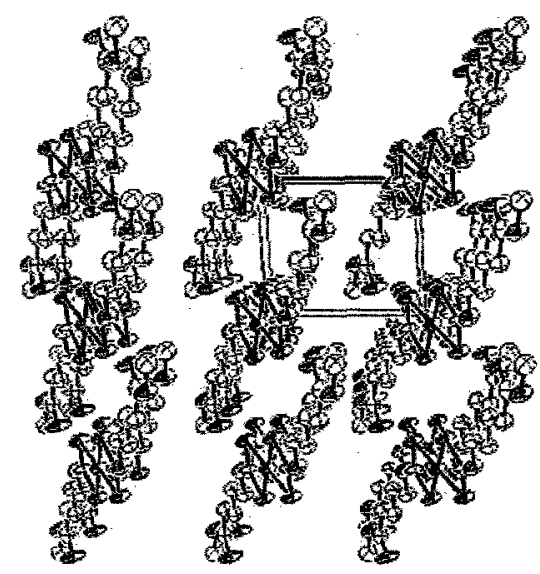

Figure 6 Molecular packing diagrams of complex 8 viewed along $c$-axis to the [010] direction.

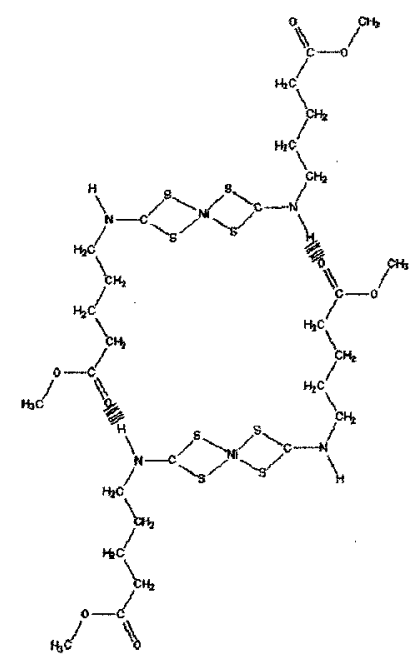

Figure 7 Intermolecular $(0.29 \mathrm{~nm})$ hydrogen bonding in complexes 8.

Based on stronger ability both of hydrogen donor and acceptor of carboxylic moiety than ester, complexes 1-4 could form complementary face-to-face hydrogen bonding between terminal carboxylic moieties as shown in Figure 3, leading to linear polymers. While, complexes 5-8 form an alternative hydrogen bonding between carbamoyl protons and ester carbonyls leading a zig-zag polymer.

\section{ACKNOWLEDGMENT}

Part of this work is supported by the Nanomaterials and Microdevices Research Center (NMRC), Graduate School of Engineering, Osaka Institute of Technology and by the Grant-in-Aid for Scientific Research, project number (C) 17550180 .

\section{REFERENCE}

[1] S. Noro, T. Nakamura, S. Kitagawa, T. Wada, Inorg. Chem., 44, 3960 (2005).

[2] R. Sekiya, S. Nishikiori, K. Ogura, Inorg. chem., 459233 (2006).

[3] P. O'Brien and R. Nomura, J. Mater. Chem. 4, 1761 (1995); R. Nomura, S. Nakamoto, and K. Shimonaka, Proc. 8th ICCE, 683 (2001); R. Nomura, and S. Hamaguchi, Trans Mater. Res. Soc. Jpn. 28, 549 (2003); R. Nomura, H. Terawaki, and O. Shimomura, ibid., 30, 1069 (2005).

[4] R. Nomura, K. Fujiwara, Trans. Mater. Res. Soc. Jpn., 28529 (2003).

[5]CrystalStructure2.00: Crystal Structure Analysis Package, Rigaku and MSC (2001)

[6]CRYSTAL Issue 10: D. J. Watkin, C. K. Prout, J. R. Carruthers, and P. W. Betteridge

[7]SIR92: A. Altomare, G. Cascarano, C. Giacovazzo, A. Guagliardi, M. Burla, G. Polidori and M. Camalli, J. Appl. Cryst., 27, 435(1994) . [8]DIRDIF99: P. T. Beurskens, G. Admiraal, G, Beurskens, W. P. Bosman, R. de Gelder, R. Israel and J. M. M. Smits, The DIRDIF-99 program system, (1999), Technical Report of the Crystallography Laboratory, University of Nijmegen, The Netherlands.

[9] M. Castillo; J. J. Criado, Inorg. Chim. Acta., 124, 127 (1986).

[10]B. Macias; M. V. Villa, Trans. Met. Chem., 20, 347 (1995).

[11]C. K. Johnson, “ORTEPIII", Oak Ridge National Laboratory, Tennessee, USA, 1976.

\section{(Recieved December 8, 2007 ; Accepted April 24, 2008)}

